\title{
The Availability of the Screw Guide Template System for the Insertion of Mid-Cervical Pedicle Screw - Technical Note
}

\author{
Shuichi Kaneyama, Taku Sugawara², Naoki Higashiyama², Masato Takabatake ${ }^{1}$, Masatoshi Sumi ${ }^{*}$ and Kazuo Mizoi ${ }^{2}$ \\ ${ }^{1}$ Department of Orthopaedic Surgery, Kobe Rosai Hospital, Kobe, Japan \\ ${ }^{2}$ Department of Neurosurgery, Akita University School of Medicine, Akita, Japan
}

\begin{abstract}
Study background: Although cervical pedicle screw method is the most stable instrumentation, which is useful for reconstruction of unstable or deformed cervical spine, to insert cervical pedicle screw accurately is sometimes challenging at the risk of the neurovascular injuries due to the anatomical features of cervical pedicles.

The purpose of this study is to introduce our Screw Guide Template (SGT) system developed to insert mid-cervical pedicle screws accurately and safely with less risk.

Method: Preoperatively, the bone image on CT was analyzed by the multiplanar imaging software and then the trajectory and the depth of the screws were designed three-dimensionally. Three types of transparent templates were created for each lamina: location template, drill guide template and screw guide template. During the operations, after engaging the templates directly with the laminae, three steps; drilling, tapping, and screwing were performed with each template. The screws were inserted accurately as we planned, which was confirmed by postoperative CT.

Case presentation: Three cases underwent posterior spinal fusion surgeries with mid-cervical pedicle screw insertion using the SGT system. The location of all screws were perfectly matched the trajectory planned preoperatively in Case 1 and 2. While, the improper templates engagement due to inadequate par spinal muscle retraction lead to the mal-positions of two screws in Case 3.

Conclusion: We demonstrated the availability of the SGT system as intraoperative screw navigation for cervical pedicle screw insertion in mid-cervical spine. Proper engaging templates and adequate muscles traction play an important role for the SGT system through the procedure.
\end{abstract}

Keywords: Spinal fixation; Screw guide template; Cervical spine; Intraoperative navigation

\section{Introduction}

Cervical pedicle screw fixation has been recognized as the most stable form of cervical instrumentation [1-3]. However, due to the anatomical features, screw insertion into mid-cervical pedicle is highly technical demanded and sometimes even challenging [4-7]. Moreover, mid-cervical pedicle screw insertion carries the risk of serious complications, such as injuries of the vertebral artery (VA), spinal cord, and nerve roots $[8,9]$. For the accurate placement of cervical screws, the evaluation of the anatomic relationship between the figuration of vertebra, the course of vertebral artery and the intended screw trajectory by three-dimensional (3D) approach is essential [10].

Pedicle screw insertion by intraoperative 3D navigation systems have been spreading, however, high radiation exposure [11,12], long operation time, high cost [12] and relative inaccuracy [13,14] are inevitable. To overcome those problems, we developed tailor-made screw guide templates with high accuracy rates of the pedicle screws insertion to C2 vertebra [15] and thoracic spine [16]. The purpose of this study is to introduce our novel SGT system in mid-cervical surgery.

\section{Methods}

\section{Imaging and tailored template}

The templates were tailored as previously described [15,16]. A spiral 3D-CT scan. (SOMATOM Sensation Cardiac, SIEMENS, Germany) was performed with a slice thickness of $0.75 \mathrm{~mm}$ before surgery on the cervical spine. The images were saved in DICOM format and exported to $3 \mathrm{D} /$ multiplanar imaging software (Ziostation; Ziosoft, Redwood city, CA, USA). Reconstructed bone images were viewed on the several optional planes and the ideal trajectories of the screws were designed three-dimensionally to insert the screws with maximum length and pass at least $2 \mathrm{~mm}$ inside of the cortical wall. The locations of the screw tips were planned to close in the anterior cortex of the vertebral body but not to penetrate the cortex. The coordinates of the bone entry points and the tips of the screws were determined (Figure 1). The bone data was transferred to a 3D modeling software Freeform (Data Design, Nagoya, Japan) and the templates and 3D models of cervical vertebrae were designed.

Then, three templates for each screw were produced: "Location templates" with $3 \mathrm{~mm}$ diameter holes were made to mark the screw entry points on the lamina. "Drill guide templates" with drill guide sleeve, 3-4 mm-diameter-cylindrical structures (depending on the diameter of the drilling tool), were created to drill the screw trajectory before screw insertion. "Screw guide templates" with a screw guide cylinder, 13-15mm-diameter-cylindrical structures (depending on the diameter of the screw driver) $30 \mathrm{~mm}$ in length, were made for screw entry point. After confirming that these templates were engaged with the vertebral posterior surface of the 3D shape of the lamina, the tailormade 3D bone models were made with non-soluble acryl by a 3D printing system, Connex 500 (Objet Ltd, Rehovot, Israel) (Figure 2).

*Corresponding author: Masatoshi Sumi, Department of Orthopaedic Surgery, Kobe Rosai Hospital 4-1-23, Kagoike-dori, Chuo-ku, Kobe 651-0053, Japan, Tel: +81-78-231-5901; Fax: +81-78-242-5316; E-mail: sumim@kobeh.rofuku.go.jp

Received November 26, 2013; Accepted December 30, 2013; Published January 3, 2014

Citation: Kaneyama S, Sugawara T, Higashiyama N, Takabatake M, Sumi M, et al. (2014) The Availability of the Screw Guide Template System for the Insertion of Mid-Cervical Pedicle Screw -Technical Note. J Spine 3: 151. doi:10.4172/21657939.1000151

Copyright: (c) 2014 Kaneyama S, et al. This is an open-access article distributed under the terms of the Creative Commons Attribution License, which permits unrestricted use, distribution, and reproduction in any medium, provided the original author and source are credited. 
Citation: Kaneyama S, Sugawara T, Higashiyama N, Takabatake M, Sumi M, et al. (2014) The Availability of the Screw Guide Template System for the Insertion of Mid-Cervical Pedicle Screw -Technical Note J Spine 3: 151. doi:10.4172/2165-7939.1000151

Page 2 of 5

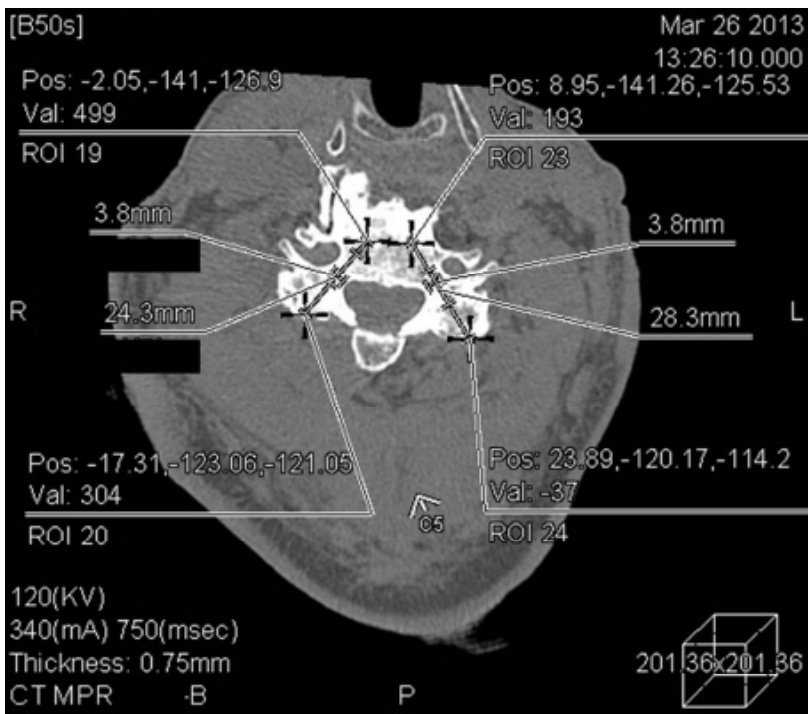

Figure 1. A screen shot of 3D/multiplanar imaging software for planning the trajectories of the screws. The ideal trajectories and their coordinates of the bone entry points and the tips of the screws were determined in a three-dimentional manner.
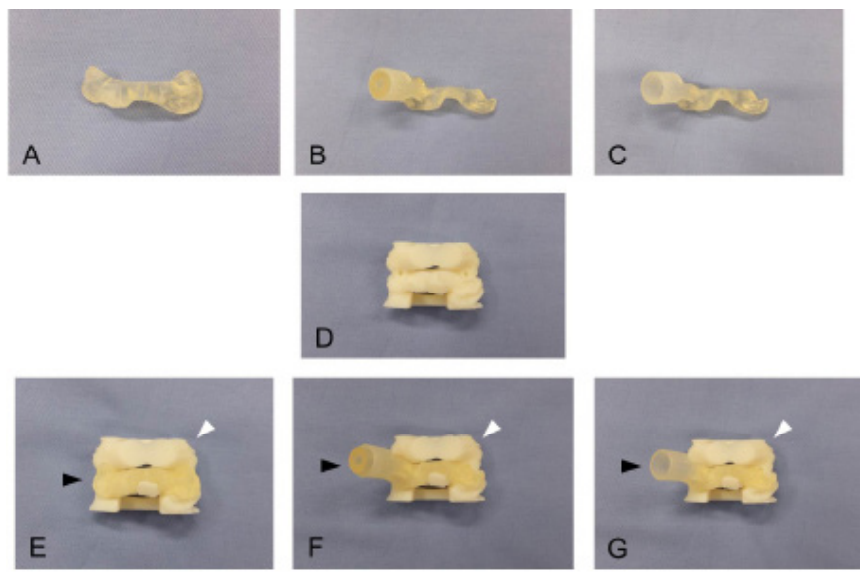

Figure 2. Three types of templates: Location template (A), drill guide template (B) and screw guide template (C), and 3D bone model (D). Each templates (black triangles) were examined for their fitting and screwing simulation was performed using 3D bone model (white triangle) before surgery (E-G).

\section{Surgery (Figure 3)}

The engagement of the templates with the laminae was examined and screwing simulation was performed before surgery. Then the templates were sterilized and used intraoperatively as navigation. During the operation, the spinous process and lateral margin of the lateral mass were exposed. Soft tissues were completely removed so that the template engaged properly. Screw navigation was then carried out with three-step procedure by the SGT system: marking the entry points using the location templates, drilling the screw trajectory using the drill guide templates and screw insertion using the screw guide templates. Fluoroscopic assistance is generally unnecessary or even impeditive because it occupied a large space and interrupts the surgeon to perform the screw insertion procedures. We use it only to confirm the screw location after insertion of all screws.

\section{Technical tips and pitfalls (Figure 4)}

In the previous study describing the accuracy of C2 cervical screw insertion by the SGT system, we reported only one screw out of 32 screws deviated from planned trajectory [15]. The deviation was occurred because muscle wall obstructed the proper placement of the templates, which gave rise to inaccurate drilling. Therefore, the engagement of the template without muscle wall obstruction is the key for the SGT system. This problem is more serious in mid-cervical spine because the pedicle axis is steeply oblique in mid-cervical vertebra (Case 3, Figure 7). To deal with it, we developed a modified Hohmann's retractor for paraspinal muscle (Case 1 and 2, Figures 5 and 6).

\section{Postoperative evaluation}

On postoperative CT, the position of the pedicle screws in the sagittal and axial planes was evaluated as follows: Grade 0 (Containing); a screw is completely within the wall of the bone structure, Grade 1 (Exposure); a screw perforates the wall of the bone structure, but more than $50 \%$ of the screw diameter remained within the bone, Grade 2 (Perforation); a screw perforates the bone structures and more than $50 \%$ of the screw diameter was outside the pedicle, Grade 3 (Penetration); a screw perforates completely outside of the bone structure.

\section{Illustrative Cases}

\section{Case 1 (Figure 5)}

A 55-year-old man presented severe cervical myelopathy due to cervical spondylosis with kyphosis. The preoperative regional kyphosis was 20 degrees at C4 to C6. Laminectomy of C3-7 and posterior fusion from C2 to T1 was performed with the SGT system. The pedicle screws were inserted into $\mathrm{C} 2, \mathrm{C} 4, \mathrm{C} 5, \mathrm{C} 7$ and $\mathrm{T} 1$ pedicles. Intraoperatively, templates securely fitted the patients' lamina with the adequate muscle retraction and the screw navigation procedure was successful.

Postoperative CT confirmed that all screws were placed perfectly at the planned location and within the pedicle cortex (Grade 0 ).

\section{Case 2 (Figure 6)}

An 85-year-old man suffering from progressive tetraplegia caused by atrantoaxial subluxation and cervical kyphoscoliosis underwent posterior fusion from $\mathrm{C} 1$ to $\mathrm{T} 1$ with the resection of the posterior arch of the atlas and laminectomy of C3-6. We inserted atrantoaxial transarticular screws and pedicle screws in $\mathrm{C} 5, \mathrm{C} 7$ and $\mathrm{T} 1$. The operation with the SGT system proceeded uneventfully, and postoperative CT demonstrated that all screws were placed at the planned location (Grade 0 ) and there was no invasion of the VA or the spinal canal.

\section{Case 3 (Figure 7)}

A 64-year-old man had a pathological fracture at $\mathrm{C} 4$ caused by the metastatic tongue cancer. He had severe neck pain, muscle weakness at right shoulder girdle and was bed-bound because of myelopathy after
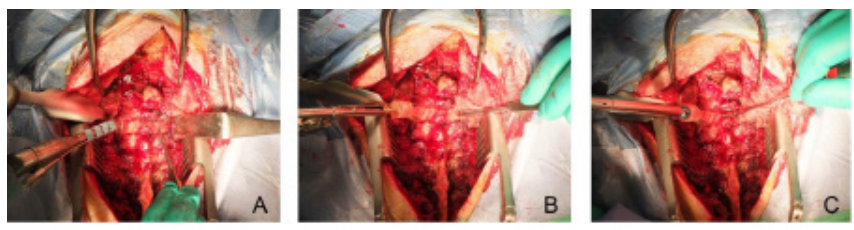

Figure 3. Screw insertion procedure with the SGT system. First, screw entry point is marked with location template $(A)$, second, drilling and tapping are performed through the drill guide template $(B)$, and last, the screw is inserted accurately with the screw guide template $(C)$. 
Citation: Kaneyama S, Sugawara T, Higashiyama N, Takabatake M, Sumi M, et al. (2014) The Availability of the Screw Guide Template System for the Insertion of Mid-Cervical Pedicle Screw -Technical Note J Spine 3: 151. doi:10.4172/2165-7939.1000151
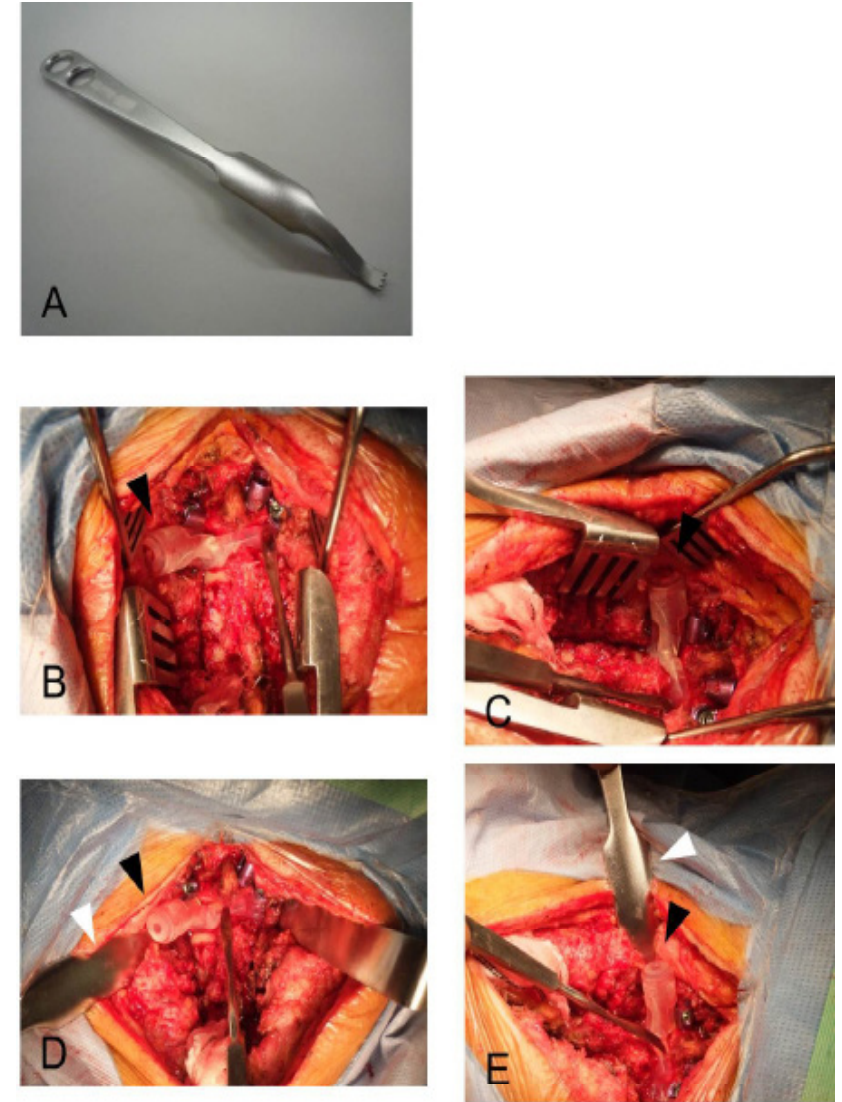

Figure 4. The retraction of paraspinal muscle using modified Hohmann's retractor. Modified Hohmann's retractor has jagged tip to firmly catch the edge of lateral mass but not to destruct it (A). Paraspinal muscle was difficult to retract with ordinal retractor, which resulted in the muscle wall obstructing the proper placement of the templates (black triangles) and the accurate aiming of the drill (B and $\mathrm{C}$ ). Modified Homann's retractor (white triangles) made it easy for surgeon to retract paraspinal muscle (black triangles) and fit the templates to patient's lamina ( $D$ and $E$ )
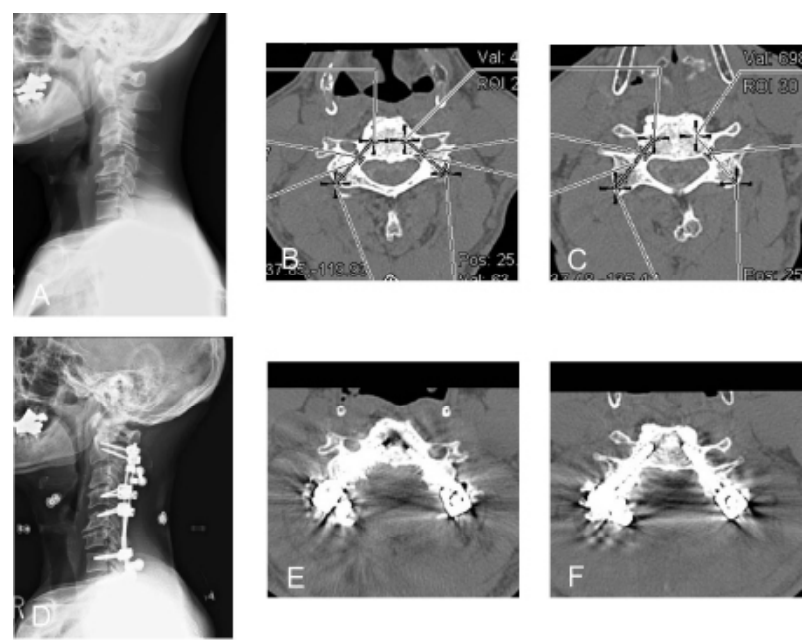

Figure 5. Preoperative radiogram of case $1(\mathrm{~A})$ and the plan of screw trajectory at $\mathrm{C} 4(\mathrm{~B})$ and $\mathrm{C} 5(\mathrm{C})$. The screw navigation procedure by the SGT was successful and all screws were placed perfectly at the planned location (D-F).
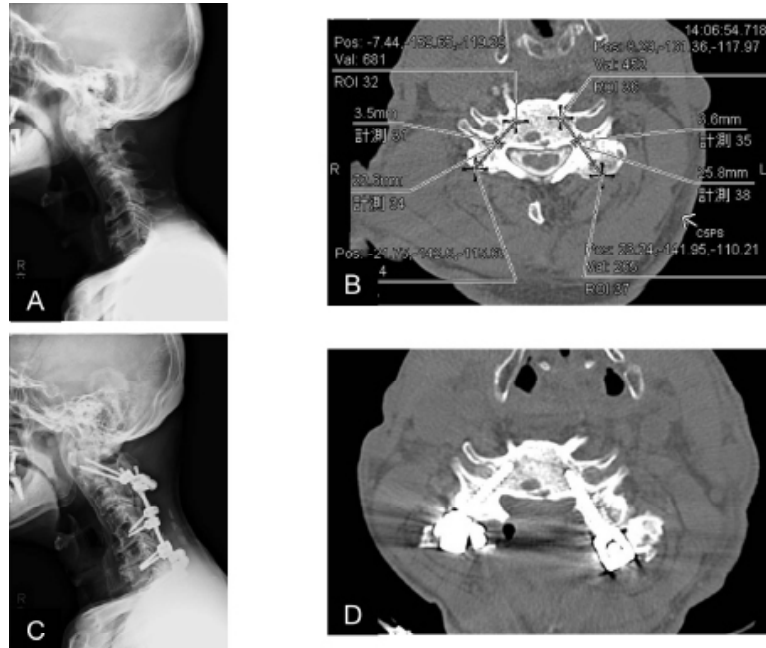

Figure 6. Preoperative radiogram of case 2 (A) and the plan of screw trajectory at C5 (B). Screws were inserted precisely even deformed vertebra using the SGT system (C and D).
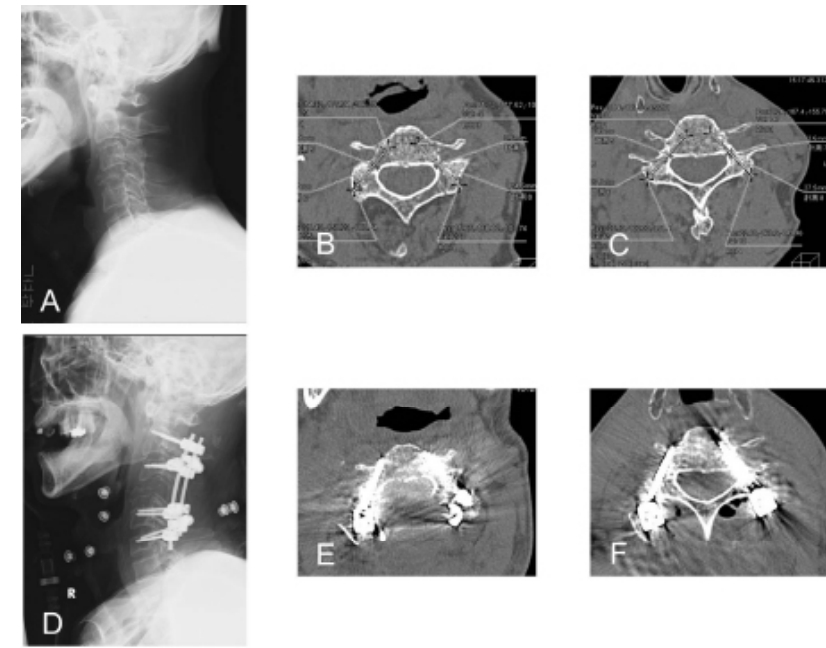

Figure 7. Preoperative radiogram of case $3(\mathrm{~A})$ and the plan of screw trajectory at C3 (B) and C6 (C). A C3-5 laminectomy with C2-C6 fusion was performed using the SGT system (D). Postoperative CT showed a Grade 2 malpositioning at right $\mathrm{C} 3$ screw $(\mathrm{E})$ and a Grade 3 malpositioning at right C6 screw (F).

spinal cord compression by tumor. Laminectomy of C3 to C5 lamina and posterior cervical fusion from $\mathrm{C} 2$ to $\mathrm{C} 6$ was performed with pedicle screws at C2, C3, C5 and C6 with the SGT system.

During the operation, paraspinal muscle could not be retracted adequately due to relatively small operative field, where the muscle wall obstructed the proper engagement of the templates and the accurate drilling except for C2. Postoperative CT showed pedicle screws were inserted in the accuracy of Grade 0 on the both sides of C2 and C5, the left side of C3 and C6. However on the right side of C3 and C6, the screws deviated from the planned trajectory and they penetrated into transverse foramen (Grade 2 and 3 respectively). Fortunately, no complication associated with these penetrations occurred.

This case suggested the importance of proper template engagement. We have developed a modified Hohmann's retractor for paraspinel muscles thereafter. 
Citation: Kaneyama S, Sugawara T, Higashiyama N, Takabatake M, Sumi M, et al. (2014) The Availability of the Screw Guide Template System for the Insertion of Mid-Cervical Pedicle Screw -Technical Note J Spine 3: 151. doi:10.4172/2165-7939.1000151

Page 4 of 5

\section{Discussion}

Cervical pedicle screw procedure provides the most rigid fixation for the cervical spine [1-3,17-19]. Therefore, it can be used for the operation of cervical spine disorder of severe deformities or instabilities [20].

However, accurate insertion of the cervical pedicle screw has been an issue due to technically challenging. Particularly, in midcervical spine, it is more challenging because of the following reasons: 1) there is few anatomical landmark to identify the proper insertion point on the posterior aspect of the lamina [5]; 2) the diameter of midcervical pedicle is small and the obliquity of the pedicle axis is steep $[5-7,21]$; 3) large anatomic variations in the size and shape are found among individuals even at the same vertebral level $[4,5,21,22]$. In addition, due to the close proximity of the spinal cord, nerve roots and vertebral arteries, there is a high risk of fatal neurovascular damage by malpositioning of the screws $[8,9]$.

The incidence rate of screw malpositioning with freehand technique in cervical spine has been reported as $6.7-29 \%[8,9,18,23]$, and this is more likely to occur in mid-cervical vertebra $[21,23]$. Yukawa et al. $[24,25]$ introduced an image-guided technique called pedicle axial view, however, it could not improve its incidence with the rate of 13.1$14.3 \%$. Aiming to solve this issue, three-dimensional approach for the anatomy of cervical vertebra and screw trajectory is developing and 3D image-based navigation systems are recently spreading [10,26-28]. However, the spinal alignment changes easily by torsion during drilling or screwing with the system and still $11.1 \%$ of screw malposition is reported by Ishikawa et al. [11].

We previously demonstrated that our SGT system provided extreme accuracy for screw insertion of $\mathrm{C} 2$ and thoracic spine $[15,16]$. The SGT system is reliable and prescribes the safe screw trajectory in a three-dimensional manner, where the direct adjustment of the templates to the target laminae prevents the registration or probing error along with the change of spinal alignment during the surgery.

Recently, personalized image-based 3D navigation template systems have been reported by several authors [29-36]. They employed only single-step drilling guide until screw insertion, where a chance for error would increase because the screw insertion procedure consists of three steps; entry point marking, screw holes drilling and screw insertion. On the contrary, our SGT screw insertion system employs a multi-step template process for the guide in all these three steps. We consider multi-step procedure should be used to minimize technical errors because each step requires each template confirming the position.

As previously described [15], the muscle wall obstructed proper placement of the templates and accurate drilling. Particularly, in the mid-cervical spine, drilling, tapping, and screw insertion can easily be misdirected laterally because of bulky paraspinal muscles. In addition, thick and solid cortex of the mid pedicle tends to cause the deviation of the trajectory laterally $[9,25,36]$. In this study, we experienced two screw malpositionings in case 3 because of improper template placement due to inadequate muscle retraction. After this case, we have performed the SGT system with the modified Hohmann's retractor and extremely high accuracy such as case 1 and 2. Although we could present only limited number of cases with preliminary data, we believe the SGT system has high reliability for cervical pedicle screw insertion.

In conclusion, we demonstrated the SGT system has high potential as a reliable intraoperative navigation system for cervical pedicle screw insertion. The engagement of the template with target lamina free from muscle wall obstruction is the key to perform the SGT system.

\section{Acknowledgement}

This research was supported by research funds to promote the hospital functions of the Japanese Labor Health and Welfare Organization.

\section{References}

1. Jones EL, Heller JG, Silcox DH, Hutton WC (1997) Cervical pedicle screws versus lateral mass screws. Anatomic feasibility and biomechanical comparison. Spine (Phila Pa 1976) 22: 977-982.

2. Kotani Y, Cunningham BW, Abumi K, McAfee PC (1994) Biomechanical analysis of cervical stabilization systems. An assessment of transpedicular screw fixation in the cervical spine. Spine (Phila Pa 1976) 19: 2529-2539.

3. Kothe R, Rüther W, Schneider E, Linke B (2004) Biomechanical analysis of transpedicular screw fixation in the subaxial cervical spine. Spine (Phila Pa 1976) 29: 1869-1875.

4. Karaikovic EE, Kunakornsawat S, Daubs MD, Madsen TW, Gaines RW Jr (2000) Surgical anatomy of the cervical pedicles: landmarks for posterior cervical pedicle entrance localization. J Spinal Disord 13: 63-72.

5. Ludwig SC, Kramer DL, Vaccaro AR, Albert TJ (1999) Transpedicle screw fixation of the cervical spine. Clin Orthop Relat Res: 77-88.

6. Panjabi MM, Shin EK, Chen NC, Wang JL (2000) Internal morphology of human cervical pedicles. Spine (Phila Pa 1976) 25: 1197-1205.

7. Sakamoto T, Neo M, Nakamura T (2004) Transpedicular screw placement evaluated by axial computed tomography of the cervical pedicle. Spine (Phila Pa 1976) 29: 2510-2514.

8. Abumi K, Shono Y, Ito M, Taneichi H, Kotani Y, et al. (2000) Complications of pedicle screw fixation in reconstructive surgery of the cervical spine. Spine (Phila Pa 1976) 25: 962-969.

9. Neo M, Sakamoto T, Fujibayashi S, Nakamura T (2005) The clinical risk of vertebral artery injury from cervical pedicle screws inserted in degenerative vertebrae. Spine (Phila Pa 1976) 30: 2800-2805.

10. Miyata M, Neo M, Ito $H$, Yoshida M, Miyaki K, et al. (2008) Is rheumatoid arthritis a risk factor for a high-riding vertebral artery? Spine (Phila Pa 1976) 33: 2007-2011.

11. Ishikawa Y, Kanemura T, Yoshida G, Matsumoto A, Ito Z, et al. (2011) Intraoperative, full-rotation, three-dimensional image (O-arm)-based navigation system for cervical pedicle screw insertion. J Neurosurg Spine 15: 472-478.

12. Shin MH, Ryu KS, Park CK (2012) Accuracy and Safety in Pedicle Screw Placement in the Thoracic and Lumbar Spines: Comparison Study between Conventional C-Arm Fluoroscopy and Navigation Coupled with O-Arm® Guided Methods. J Korean Neurosurg Soc 52: 204-209.

13. Ito H, Neo M, Yoshida M, Fujibayashi S, Yoshitomi H, et al. (2007) Efficacy of computer-assisted pedicle screw insertion for cervical instability in RA patients. Rheumatol Int 27: 567-574

14. Yang YL, Zhou DS, He JL (2013) Comparison of isocentric C-arm 3-dimensional navigation and conventional fluoroscopy for $\mathrm{C} 1$ lateral mass and $\mathrm{C} 2$ pedicle screw placement for atlantoaxial instability. J Spinal Disord Tech 26: 127-134.

15. Kaneyama S, Sugawara T, Higashiyama N, Takabatake M, Sumi M, et al (2013) The accuracy of cervical screw insertion with the Screw Guide Template (SGT) system for C2 vertebra. Proceedings of the Cervical Spine Research Society Asia Pacific Section.

16. Sugawara T, Higashiyama N, Kaneyama S, Takabatake M, Watanabe N, et al (2013) Multistep pedicle screw insertion procedure with patient-specific lamina fit-and-lock templates for the thoracic spine: clinical article. J Neurosurg Spine 19: 185-190.

17. Abumi K, Itoh H, Taneichi H, Kaneda K (1994) Transpedicular screw fixation for traumatic lesions of the middle and lower cervical spine: description of the techniques and preliminary report. J Spinal Disord 7: 19-28.

18. Abumi K, Kaneda K (1997) Pedicle screw fixation for nontraumatic lesions of the cervical spine. Spine (Phila Pa 1976) 22: 1853-1863.

19. Klekamp JW, Ugbo JL, Heller JG, Hutton WC (2000) Cervical transfacet versus lateral mass screws: a biomechanical comparison. J Spinal Disord 13: 515-518.

20. Abumi K, Takada T, Shono Y, Kaneda K, Fujiya M (1999) Posterio occipitocervical reconstruction using cervical pedicle screws and plate-rod systems. Spine (Phila Pa 1976) 24: 1425-1434. 
Citation: Kaneyama S, Sugawara T, Higashiyama N, Takabatake M, Sumi M, et al. (2014) The Availability of the Screw Guide Template System for the Insertion of Mid-Cervical Pedicle Screw -Technical Note J Spine 3: 151. doi:10.4172/2165-7939.1000151

21. Karaikovic EE, Daubs MD, Madsen RW, Gaines RW Jr (1997) Morphologic characteristics of human cervical pedicles. Spine (Phila Pa 1976) 22: 493-500.

22. Ebraheim NA, Xu R, Knight T, Yeasting RA (1997) Morphometric evaluation of lower cervical pedicle and its projection. Spine (Phila Pa 1976) 22: 1-6.

23. Kast E, Mohr K, Richter HP, Börm W (2006) Complications of transpedicular screw fixation in the cervical spine. Eur Spine J 15: 327-334.

24. Yukawa $Y$, Kato F, Ito K, Horie $Y$, Hida T, et al. (2009) Placement and complications of cervical pedicle screws in 144 cervical trauma patients using pedicle axis view techniques by fluoroscope. Eur Spine J 18: 1293-1299.

25. Yukawa Y, Kato F, Yoshihara H, Yanase M, Ito K (2006) Cervical pedicle screw fixation in 100 cases of unstable cervical injuries: pedicle axis views obtained using fluoroscopy. J Neurosurg Spine 5: 488-493.

26. Hott JS, Deshmukh VR, Klopfenstein JD, Sonntag VK, Dickman CA, et al. (2004) Intraoperative Iso-C C-arm navigation in craniospinal surgery: the first 60 cases. Neurosurgery 54: 1131-1136.

27. Ito $Y$, Sugimoto $Y$, Tomioka M, Hasegawa $Y$, Nakago K, et al. (2008) Clinical accuracy of $3 \mathrm{D}$ fluoroscopy-assisted cervical pedicle screw insertion. J Neurosurg Spine 9: 450-453.

28. Rajasekaran S, Vidyadhara S, Ramesh P, Shetty AP (2007) Randomized clinical study to compare the accuracy of navigated and non-navigated thoracic pedicle screws in deformity correction surgeries. Spine (Phila Pa 1976) 32 E56-64.

29. Berry E, Cuppone M, Porada S, Millner PA, Rao A, et al. (2005) Personalised image-based templates for intra-operative guidance. Proc Inst Mech Eng $\mathrm{H}$ 219: 111-118.

30. Kawaguchi Y, Nakano M, Yasuda T, Seki S, Hori T, et al. (2012) Development of a new technique for pedicle screw and Magerl screw insertion using a 3-dimensional image guide. Spine (Phila Pa 1976) 37: 1983-1988.

31. Lu S, Xu YQ, Chen GP, Zhang YZ, Lu D, et al. (2011) Efficacy and accuracy of a novel rapid prototyping drill template for cervical pedicle screw placement. Comput Aided Surg 16: 240-248.

32. Lu S, Xu YQ, Lu WW, Ni GX, Li YB, et al. (2009) A novel patient-specific navigational template for cervical pedicle screw placement. Spine (Phila $\mathrm{Pa}$ 1976) 34: E959-966

33. Lu S, Xu YQ, Zhang YZ, Xie L, Guo H, et al. (2009) A novel computer-assisted drill guide template for placement of C2 laminar screws. Eur Spine J 18: 13791385.

34. Owen BD, Christensen GE, Reinhardt JM, Ryken TC (2007) Rapid prototype patient-specific drill template for cervical pedicle screw placement. Comput Aided Surg 12: 303-308.

35. Ryken TC, Kim J, Owen BD, Christensen GE, Reinhardt JM (2009) Engineering patient-specific drill templates and bioabsorbable posterior cervical plates: a feasibility study. J Neurosurg Spine 10: 129-132.

36. Ryken TC, Owen BD, Christensen GE, Reinhardt JM (2009) Image-based dril templates for cervical pedicle screw placement. J Neurosurg Spine 10: 21-26. 